2. Оленина О.А., Ступникова Е.A. Historical aspects of the development of the estimated pricing in Russia (Исторические аспекты развития сметного ценообразования в России) // НАУКА И ТЕХНОЛОГИИ Издательство: SCIEURO (Лондон). 2016. № 2. С. 113 - 122.

3. Рубченко Д.С., Кузнецова А.Э. Особенности формирования укрупненных нормативов на строительство комплексных линейных объектов железнодорожной инфраструктуры // Строительство. Экономика и управление. 2017. № 4 (28). С. 7 - 16.

Petrovskiy Alexander Ilyich, Postgraduate Student of the Department of Transport Infrastructure Economics and construction business management», Russian University of transport (MIIT) (9b9, Obrazcova St., Moscow, 127994, Russian Federation). E-mail: elbrus007oor@yandex.ru

\title{
CONSOLIDATED STANDARDS AS A COST-EFFECTIVE METHOD FOR DETERMINING THE COST OF CONSTRUCTION \\ Abstract
}

This article discusses issues related to the specifics of determining the cost of construction of railway transport infrastructure using enlarged standards and cost indicators of similar objects. Two methods for determining the cost of construction are compared.

Keywords: construction cost, infrastructure, railway transport, enlarged standards, pre-project stage.

\section{References}

1. Kapustina N.V., Stupnikova E.A., Olenina O.A., Gerasimov M.M. Klassifikaciya faktorov riska investicionnyh proektov razvitiya transportnoj infrastruktury // Gosudarstvennoe i muni-cipal'noe upravlenie. Uchenye zapiski. 2020. № 1. P. 126-130.

2. Olenina O.A., Stupnikova E.A. Historical aspects of the development of the estimated pricing in Russia (Istoricheskie aspekty razvitiya smetnogo cenoobrazovaniya v Rossii) // NAUKA I TEKHNOLOGII Izdatel'stvo: SCIEURO (London). 2016. № 2. P. 113 - 122.

3. Rubchenko D.S., Kuznecova A.E. Osobennosti formirovaniya ukrupnennyh normativov na stroitel'-stvo kompleksnyh linejnyh ob"ektov zheleznodorozhnoj infrastruktury // Stroitel'stvo. Ekonomika i upravlenie. 2017. № 4 (28). P. 7 - 16.

\section{ПРОФЕССИОНАЛИЗМ КАК ОСНОВА ДЕЯТЕЛЬНОСТИ МУНИЦИПАЛЬНЫХ СЛУЖАЩИХ}

\author{
Серикова аспирант кафедры социологии, Южно-Российский институт \\ Eкатерина управления - филиал Российской академии народного хозяйства \\ Юрьевна осударственной службы при Президенте РФ \\ (344002, Россия, г. Ростов-на-Дону, ул. Пушкинская, 70/54). \\ E-mail: seu-7753191@inbox.ru
}

\begin{abstract}
Аннотация
В данной статье автор раскрывает такие понятия как муниципальная служба как особый вид профессиональной деятельности, историческое формирование и традиции местного самоуправления в России, профессионализм, профессионал в мунищипальной службе и какие факторы влияют на развитие профессионализма у муниципальных служащих. Автор рассматривает взгляды современных ученых по исследуемому вопросу.

Ключевые слова: муниципальная служба в российском обществе, профессия, профессионализм, кадры страны, инновационный путь развития муниципальной службы, управленческая квалификация служащих, мунищипальная служба как особый вид профессиональной деятельности.

Для сегодняшней России остается крайне важным вопрос профессионализма и нехватки необходимых компетенций, которыми должны обладать работники муниципального аппарата. Высшее организационное руководство страны неоднократно отмечало недостаточное наличие знаний современной науки управления у сотрудников муниципальной службы.

Муниципальная служба в России имеет глубокое историческое прошлое, а традиции сквозь глубины времени уходят более чем на тысячи лет. Зарождение основ государственного управления и государственной службы, происходило во времена Древней Руси, когда оно было неразделимо с организацией военных сил государства.

B XVIII веке при Петре I появилось право по вступлению на гражданскую службу, согласно которому на государственную службу разрешалось пойти детям потомственных дворян, священников, купцов и придворных служителей.
\end{abstract}


Есть еще один интересный исторический факт. С 1796 г. по 1847 г. численность чиновников возросла в 4 раза, а с 1796г.-1857г. - почти в 6 раз. Этому способствовал стремительный рост государственного аппарата. Следует отметить, что численность населения за этот период выросла по сравнению с ростом количества госслужащих всего лишь в 2 раза. Это наглядный пример того, что государственный аппарат в 1-й половине XIX века рос почти в 3 раза быстрее, чем население.

В это время государство продолжало поддерживать и укреплять систему иерархии. Так, во время правления Николая I были введены новые требования к соблюдению особенного «дресскода» в одежде. Появилась рекомендация для чиновников надевать парадный костюм, в зависимости от своего социально положения. Кроме того, появилось особое официальное обращение к чиновникам высшего ранга. Еще одним важным признаком расслоения чиновничества, присущим этому историческому периоду, стал тот факт, что столичная элита отделилась от провинциальной. Появился новый признак разделения элит территориальный. Провинциал, безусловно, стоял ближе к жизни. Местных чиновников столичная бюрократия безусловно считала только исполнителями, оставив за собой привилегию управления и контроля.

И если изначально за «квалифицированных» чиновников традиционно принято было считать людей, которые поступали на службу к князьям, то в советский период развития муниципальной службы кадровый состав был создан представителями разных профессий, многие из которых получили свой опыт работы еще в партийно-советском аппарате. В это же время был широко распространен принцип рационального распределения кадров по территории страны. И если даже на закате советской эпохи получалось поддерживать необходимый уровень профессионального развития кадров, то в современной России существуют очевидная недоработка в получении необходимой квалификации и профессиональной базы сотрудников муниципального уровня власти [1].

Эти и другие факторы повлияли на то, что в конце 20 - начале 21 веков появилась необходимость реформирования местного самоуправления.

В наши дни Муниципальная служба в российском обществе приобретает черты профессии. Но, несмотря на это, все так же остается актуальным вопрос о подготовке профессионалов, которые смогут эффективно осуществлять этот род деятельности.

Кто же он, профессионал своего дела, муниципальный служащий 21 века?

Нельзя не согласиться с мнением Президента Российской Федерации В.В. Путина: «Кадры страны - составная часть совокупного национального богатства России, ее важнейший ресурс - более важный, чем нефть, газ, другие природные достояния. Углеводородные ресурсы - предельны, ограничены, людские - неисчерпаемы. Нефть и газ - рано или поздно закончатся, а кадры страны с их интеллектом и профессиональными способностями - вечны. Очевидно, что преодолеть кризис можно с помощью не долларового, а человеческого капитала. Поэтому переход на инновационный путь развития страны должен быть связан, прежде всего, с масштабными инвестициями в человеческий капитал. Развитие профессионального потенциала человека - это не только сегодня основная цель государства, но и в долгосрочной перспективе абсолютный национальный приоритет России» ${ }^{.}$

Сегодня в век технологий и конкурентоспособности, развитые страны уже давно осознали важность профессионализма человека в организации. И признали его основной производительной силой. Придается большое значение человеческому фактору, его качеству, потенциалу и профессионализму.

В современном социальном дискурсе за последние десятилетия можно проследить изменения, происходящие в управлении персоналом: уход от иерархического управления, происходит понимание того, что каждому члену коллектива нужен свой индивидуальный подход. Сотрудник начинает восприниматься не только как исполнитель, но и как личность, имеющая права выбора для себя интересной перспективной работы, обсуждения на равных с потенциальным работодателем оплаты своего труда, возможность реализовывать свой потенциал и способности, расти и развиваться в выбранном направлении. Теперь в ситуации конкурентоспособности обсуждение предлагаемой работы ведется «на равных» и право выбора имеют обе стороны. Данная тенденция в дальнейшем будет только набирать обороты. Такой подход формирует новое отношение к подходу в понимании, что такое профессионализм [2].

Понятие профессионализм широко употребляется в современной научной литературе. Сразу необходимо отметить, что понятие профессионализм имеет различные грани и имеет множество составляющих элементов.

\footnotetext{
1 Официальный сайт конкурса «Лучшие кадровые технологии Санкт-Петербурга». [Электронный ресурс]: Режим доступа: https://kkt.kadrsov.ru/storage/app/uploads/public/59d/773/3b9/59d7733b9ba01873777552.pdf (дата обращения: 07.04.2020).
} 
Фред Хойл рассматривал профессионализм в качестве определенной сегментации, которая может использоваться людьми определенной профессии для улучшения своего социального статуса. Согласно мнению Л. Эванса, профессионализм отражает такое качество как индивидуальность работника, занятого в определенной профессиональной среде. Эта позиция схожа с мнением российского социального научного сообщества, профессионализм - это то, что индивид производит, а не то, что хочет от него правительство и организация.

Термин «профессия» в толковых словарях имеет множество различных трактовок. Одними из широко используемых являются следующие: как род трудовой деятельности, занятий, определяемый разделением труда и его функциональным содержанием; и как большая группа людей, объединённая общим родом занятий, трудовой деятельностью [3].

Обращаясь к истории терминологии, можно проанализировать, что впервые отметил государственную службе как профессию мировой немецкий философ, социолог и политический экономист Макс Вебер. Он сопоставлял два понятия «профессия» и «призвание» (в переводе с немецкого эти оба понятия обозначаются термином «Beruf»). М. Вебер относится к числу ученых, которые хорошо разбирались в области политэкономии, права, социологии и философии. Он считал, что понятие профессионального призвания государственного служащего напрямую сопряжёно с внутренними ценностями и со своим внутренним отношением к внешнему миру самого человека. М. Вебер был уверен, что подлинной профессией настоящего чиновника не может быть политика [4].

П. Сорокин придерживается мнения, что профессия формирует основные социальные качества человека, она формирует его интересы и убеждения по своему роду и подобию.

Р.К. Овчаренко в своей монографии «Управление государственной гражданской службы» рассматривает, профессию как вид деятельности, благодаря которой человек приобретает социальный статус и профессиональную идентичность. И осваивая определенный кодекс поведения, индивид приобщается к социально-культурной среде [5].

Термины профессия, профессионал и профессионализм похожи не только по звучанию, но их еще объединяет один и тот же латинский корень, "fess", что обозначает в переводе - профессия.

Выбор профессии - это выбор правды. Для государственного и муниципального служащего это означает знание и соблюдение Закона, в первую очередь самими служащими. Муниципальная служба - это особый вид профессиональной деятельности и среди основных требований, предъявляемых к муниципальным работникам, является наличие профессионализма. Применительно к муниципальной службе оно может быть определено как качество, характеризующее глубокое и всестороннее знание и владение практическими навыками и умениями в целом в муниципальном управлении и в отраслевом направлении, в частности.

В процессе формирования и развития профессионализма и управленческой квалификации у муниципальных служащих образование имеет важнейшую роль. Основополагающим звеном здесь должно стать непрерывное образование, охватывающее не только теоретические знания. Необходимо действовать на опережение. Будущие муниципальные служащие должны научиться диагностировать социально-экономические процессы как в стране, так и в том локальном социуме, в котором будет проходить их служба. А также уметь прогнозировать и выявлять наиболее острые проблемы, с которыми придётся иметь дело [6].

Необходим инновационный подход и в организации переподготовки и повышению квалификации для уже действующих муниципальных служащих.

Процесс переподготовки обязательно должен осуществляться с учетом различий и разницы от имеющейся стартовой подготовки, и уровня образования работника. Для реализации этого нужно обеспечить непрерывное обучение: самообразование, по индивидуальному плану (контролируемое непосредственным руководителем), участие в специальных семинарах по профильным вопросам муниципального органа. Служащие должны отправляться на стажировки в передовые научные предприятия муниципальной службы, и крупнейшие учебные учреждения, в том числе международные для обмена опытом.

Часто происходит своего рода несоответствие реалий действительности, когда педагогический состав действует согласно устаревшим воззрениям, а проходящие обучение служащие превосходят по своим знаниям самих преподавателей. Происходит это потому, что преподаватели зачастую опираются только на теоретические представления о функционировании органов местного самоуправления, а обучающиеся лучше знают дело «изнутри» и лучше с практической стороны.

Невозможно рассчитывать на успех образовательного процесса, не изменив эту ситуацию. Таким образом, для того что бы перестройка существующей образовательной системы имела эффективное влияние на уровень профессионализма муниципальных служащих, она должна быть комплексной и действовать в ногу со временем или даже опережающими темпами [7]. 
Существует еще один важный показатель, который положительно влияет на развитие у муниципальных служащих такого качества, как профессионализм, - это профессиональная культура. Муниципальная служба как профессия формально утвердилась, но выполнение профессиональных обязанностей служащими пока не выполняются должным образом и об этом свидетельствует наличие такого негативного явления среди служащих, как протекционизм. Протекционизм означает прием на должности и последующее карьерное продвижение не самых достойных кандидатов, а удобных и выгодных отдельным лицам в муниципальной службе.

К сожалению, протекционизм в муниципальной службе стал сегодня неформальной нормой. Проведение конкурса на замещение должностей часто несет формальный характер, и победивший кандидат определен заранее.

Такой подход еще на этапе отбора кандидатов, неблагоприятного влияет на климат в коллективе - возникает сильная зависимость подчиненного от начальника. Это оказывает отрицательное влияние на развитие профессионализма у служащих, так как появляются социально негативные качества, такие как подхалимство, отсутствие собственного мнения, низкий уровень инициативности.

В силу перечисленных причин сегодня в муниципальной службе важно развить у служащих стремление к повышению своего уровня профессионализма посредством профессиональной культуры, которая через неформальные нормы, ценности и правила сможет регулировать профессиональную деятельность служащих, и благодаря чему будет обеспечиваться определенное отношение людей к своим профессиональным обязанностям, что в свою очередь является одним из элементов профессионализма.

Мало кто знает из муниципальных служащих, что у них есть свой профессиональный праздник. Когда и в следствие чего же, он появился?

10 июня 2012 г. Президент России Владимир Путин подписал указ, которым установил отмечать День местного самоуправления 21 апреля, в день издания в 1785 г. Жалованной грамоты городам, положившей начало развитию российского законодательства о местном самоуправлении [8].

Муниципальная служба в этом смысле - одна из профессий, для обладателя которой также необходимы определенные ценности и убеждения.

Служащим необходимо не только знать, но и применять на практике правовые и этические нормы в рамках своей служебной деятельности. В профессиональных сообществе муниципальных служащих складываются свои этические кодексы, особая культура, нормы, профессиональный статус. Характерной чертой такого подхода может являться профессиональная честь и достоинство. Такие качества необходимо взращивать для поддержки благоприятной репутации всей муниципальной службы в глазах общественности. Так же, как и беспристрастность при выполнении служебных задач.

Совершенствование профессионального развития муниципальных служащих благоприятно влияет на управленческую среду социальное взаимодействие работников, на их дисциплину, и отношение к своей трудовой деятельности. Профессиональные способности муниципального служащего и рациональное использование профессионального опыта - это профессиональный капитал организации.

В заключении хотелось бы подчеркнуть, исторически так сложилось, что формирование местного самоуправления в нашей стране из-за перестроек и разделения власти переживало серьезные исторические кризисы в своем развитии. До сих пор остается низкой степень эффективности развития муниципальных округов страны, большинство из которых нуждаются в квалифицированных кадрах. Поэтому в деятельности муниципальной службы необходимо больше уделять внимание вопросам муниципальной кадровой политики. Она делает стабильным муниципальное управление и обеспечивает муниципальную службу опытными и высококвалифицированными кадрами.

\section{Литература}

1. Антошин B.A., Федоровских А.А. Государственная и муниципальная служба. Екатеринбург: УрИУ РАНХиГС, 2017. 196 с.

2. Маслова Т.С.. Профессионализм и профессиональная культура в современных и социологических исследованиях // Гуманитарий Юга России. 2016. №6. [Электронный ресурс]: Режим доступа: https://cyberleninka.ru/article/n/professionalizm-i-professionalnaya-kultura-v-sovremennyh-isotsiologicheskih-issledovaniyah (дата обращения: 15.10.2020).

3. Зинченко Я.Г. Профессионализация государственной гражданской службы. Монография. Ростов н/Д.: Изд-во СКАГС, 2011. 136с.

4. Вебер М. Политика как призвание и профессия// Вебер М. Избранные произведения. М., 1990.808 с. 
6. Овчаренко Р.К. Управление государственной гражданской службой: монография. Ростов н/Д: Антей, 2011. $360 \mathrm{c.}$

7. Дорофеев А.В. Кадровый состав муниципальных служащих как ресурс развития муниципалитетов // Среднерусский вестник общественных наук. 2014. №5 (35). [Электронный ресурс]: Режим доступа: https://cyberleninka.ru/article/n/kadrovyy-sostav-munitsipalnyh-sluzhaschih-kak-resurs-razvitiyamunitsipalitetov (дата обращения: 13.09.2020).

8. Мифтахетдинова 3.X. Профессиональная компетентность муниципальных служащих как условие повышения качества жизни населения // ВЭПС. 2014. №3. [Электронный ресурс]: Режим доступа: https://cyberleninka.ru/article/n/professionalnaya-kompetentnost-munitsipalnyh-sluzhaschih-kak-usloviepovysheniya-kachestva-zhizni-naseleniya (дата обращения: 15.10.2020).

9. Забнева Э.И. Особенности становления муниципальной службы как профессиональной деятельности // Вестник экономики, права и социологии. 2015. № 2. С. 205 - 208.

Serikova Ekaterina Yurievna, Postgraduate Student, Department of Sociology, Faculty of Political Science, South-Russian Institute of Management - branch of Russian Presidential Academy of National Economy and Public Administration (70/54, Pushkinskaya St., Rostov-on-Don, 344002, Russian Federation).

E-mail: cappuccino_cat@mail.ru

\section{PROFESSIONALISM AS THE BASIS OF ACTIVITIES OF MUNICIPAL EMPLOYEES}

\section{Abstract}

In this article, the author reveals such concepts as municipal service as a special type of professional activity, historical formation and traditions of local self-government in Russia, professionalism, a professional in municipal service and what factors affect the development of professionalism among municipal employees. The author examines the views of modern scientists on the issue under study.

Keywords: municipal service in Russian society, profession, professionalism, personnel of the country, innovative path of development of municipal service, managerial qualification of employees, municipal service as a special type of professional activity.

\section{References}

1. Antoshin V.A., Fedorovskih A.A. Gosudarstvennaya i municipal'naya sluzhba. Ekaterinburg: UrIU RANHiGS, 2017. 196 p.

2. Maslova T.S.. Professionalizm i professional'naya kul'tura v sovremennyh i sociologicheskih is-sledovaniyah // Gumanitarij YUga Rossii. 2016. №6. [Elektronnyj resurs]: Rezhim dostupa:

https://cyberleninka.ru/article/n/professionalizm-i-professionalnaya-kultura-v-sovremennyh-isotsiologicheskih-issledovaniyah (data obrashcheniya: 15.10.2020).

3. Zinchenko YA.G. Professionalizaciya gosudarstvennoj grazhdanskoj sluzhby. Monografiya. Rostov n/D.: Izd-vo SKAGS, 2011. $136 \mathrm{p}$.

4. Veber M. Politika kak prizvanie i professiya// Veber M. Izbrannye proizvedeniya. M., 1990. 808 p.

6. Ovcharenko R.K. Upravlenie gosudarstvennoj grazhdanskoj sluzhboj: monografiya. Rostov n/D: Antej, 2011. $360 \mathrm{p}$.

7. Dorofeev A.V. Kadrovyj sostav municipal'nyh sluzhashchih kak resurs razvitiya municipalitetov // Srednerusskij vestnik obshchestvennyh nauk. 2014. №5 (35). [Elektronnyj resurs]: Rezhim dostupa: https://cyberleninka.ru/article/n/kadrovyy-sostav-munitsipalnyh-sluzhaschih-kak-resurs-razvitiyamunitsipalitetov (data obrashcheniya: 13.09.2020).

8. Miftahetdinova Z.H. Professional'naya kompetentnost' municipal'nyh sluzhashchih kak uslovie povysheniya kachestva zhizni naseleniya // VEPS. 2014. №3. [Elektronnyj resurs]: Rezhim dostupa:

https://cyberleninka.ru/article/n/professionalnaya-kompetentnost-munitsipalnyh-sluzhaschih-kak-usloviepovysheniya-kachestva-zhizni-naseleniya (data obrashcheniya: 15.10.2020).

9. Zabneva E.I. Osobennosti stanovleniya municipal'noj sluzhby kak professional'noj deyatel'-nosti // Vestnik ekonomiki, prava i sociologii. 2015. № 2. P. 205 - 208. 